\title{
Long-Lasting Insecticide Net Ownership, Access and Use in Southwest Ethiopia: A Community-Based Cross-Sectional Study
}

\author{
Dinberu Seyoum ${ }^{1,2, *}$, Niko Speybroeck ${ }^{1}$, Luc Duchateau ${ }^{3}$, Patrick Brandt ${ }^{4}$ and \\ Angel Rosas-Aguirre 1,5 \\ 1 Institute of Health and Society (IRSS), Université Catholique de Louvain, 1200 Brussels, Belgium; \\ speybroeck@uclouvain.be \\ 2 Department of Statistics, Natural Science College, Jimma University, Jimma 378, Ethiopia \\ 3 Biometrics Research Group, Faculty of Veterinary Medicine, Ghent University, 9000 Ghent, Belgium; \\ Luc.Duchateau@ugent.be \\ 4 School of Economic, Political and Policy Sciences, The University of Texas, Dallas, TX 75080, USA; \\ pbrandt@utdallas.edu \\ 5 Institute of Tropical Medicine "Alexander von Humboldt", Universidad Peruana Cayetano Heredia, \\ Lima 31, Peru; angelrosasa@gmail.com \\ * Correspondence: dinberu.seyoum@gmail.com
}

Received: 19 August 2017; Accepted: 24 October 2017; Published: 27 October 2017

\begin{abstract}
Introduction: A large proportion of the Ethiopian population (approximately 68\%) lives in malaria risk areas. Millions of long-lasting insecticide treated nets (LLINs) have been distributed as part of the malaria prevention and control strategy in the country. This study assessed the ownership, access and use of LLNs in the malaria endemic southwest Ethiopia. Methods: A community-based cross-sectional study was conducted in southwest Ethiopia during October-November 2015, including 836 households from sixteen villages around Gilgel-Gibe dam area. Indicators of ownership, access and use of LLINs were derived following the Roll Back Malaria (RBM) guidelines. Factors associated with failure for both LLIN access and use were analysed at household level using a multivariate logistic regression model. Results: The proportion of households with at least one LLIN was $82.7 \%$ (95\% CI: 80.0, 85.1). However, only $68.9 \%$ (95\% CI: 65.6, 71.9) had enough LLINs to cover all family members (with $\geq$ one LLIN for every two persons). While $75.3 \%$ (95\% CI: 68.4, 83.0) of the population was estimated to have accessed to LLINs, only $63.8 \%$ ( $95 \%$ CI: 62.3, 65.2) reported to have used a LLIN the previous night. The intra-household gap (i.e., households owning at least one LLIN, but unable to cover all family members) and the behavioral gap (i.e., household members who did not sleep under a LLIN despite having access to one) were $16.8 \%$ and $10.5 \%$, respectively. Age, marital status and education of household heads, as well as household size and cooking using firewood were associated with the access to enough LLINs within households. Decreased access to LLINs at households was the main determinant for not achieving $\geq 80 \%$ household members sleeping under a LLIN the previous night. Other associated factors were household size and education level of household head. Conclusions: LLIN coverage levels in study villages remain below national targets of $100 \%$ for ownership and $80 \%$ for use. The access to enough LLINs within the households is the main restriction of LLIN use in the study area.
\end{abstract}

Keywords: long lasting insecticide treated net; access; ownership; LLIN use; Ethiopia

\section{Introduction}

Malaria is one of the most important public health problems worldwide with about 3.5 billion people living at malaria risk in 2015, and millions of them still not accessing preventive and control 
measures, especially in sub-Saharan African countries [1]. In Ethiopia, about $68 \%$ of the total population resides in areas with high malaria risk [2], and 2,174,707 cases and 662 deaths due to malaria were reported in 2014-2015 [3].

Insecticide-treated bed nets (ITNs), more specifically long lasting insecticide-treated nets (LLINs), are known to be highly effective in reducing malaria morbidity and mortality [4-6]. The World Health Organization (WHO) recommends achieving high LLIN coverage rates in endemic areas through free-of-charge or highly subsidized delivery of LLINs to maximize the effectiveness of control programs [7]. According to WHO estimates [1], control interventions averted 663 million malaria cases in sub-Saharan Africa between 2001 and 2015 [1], and the use of LLINs contributed about $69 \%$ to those averted cases. However, reaching universal coverage and use of LLINs remains challenging in the African continent. In $2015,67 \%$ of households had access to an ITN but only $55 \%$ of the population slept under an ITN the previous night [1].

The distribution of LLINs is a key intervention for preventing malaria disease in Ethiopia [7-10]. According to the Ethiopian Ministry of Health (MoH), near to 20 million LLINs were delivered in the country between 2013 and 2015 with participation of health workers, community volunteers, and the local authorities [2,7]. Despite these efforts, Ethiopian malaria goals for 2015 in malaria endemic areas (i.e., $100 \%$ of LLIN coverage, and more than $80 \%$ of use of LLINs) have not been achieved [11-14]. The percentage of households with at least one LLIN at country level was $64.0 \%$ in 2015 , and regions such as Oromia presented even lower LLIN coverage than the national average [8].

In addition to periodic data from household surveys aiming to assess whether the population at risk receives enough nets and uses them properly [15], the design of effective strategies based on the distribution of ITNs/LLINs requires information about the factors that can affect the success and failure for getting high levels of LLIN access, ownership and use [1,4,16]. LLIN access is measured at household level and takes into account the number of available LLINs for the total household members, but very few studies have investigated risk factors associated with poor access to LLINs (i.e., less than one LLIN for every two household members) $[5,14,17,18]$. Instead, several studies have explored the determinants of ITN/LLIN ownership and use. The demographics, the socio-economic status, the knowledge about malaria and the protective effect of LLINs, and the intensity of malaria transmission had been identified as factors for owning LLIN in eastern and southwest Ethiopia $[19,20]$. Besides the demographic characteristics of individuals, the sleeping patterns, the family size, and the net type have been also reported among the factors associated with the LLIN use in Amhara Regional States of Ethiopia and western Kenya [9,14,21,22]. Here, we present a cross-sectional study that reports the levels of ownership, access and use of LLINs in southwest Ethiopia in 2015. We identify the factors that predict failure of LLIN access and use.

\section{Materials and Methods}

\subsection{Study Area}

The study was conducted in Jimma zone, Oromia region of Ethiopia, $260 \mathrm{~km}$ southwest of Addis Ababa, at an altitude of $1734-1864 \mathrm{~m}$ above sea level, between latitudes $7^{\circ} 42^{\prime} 50^{\prime \prime} \mathrm{N}$ and $07^{\circ} 53^{\prime} 50^{\prime \prime} \mathrm{N}$ and between longitudes $37^{\circ} 11^{\prime} 22^{\prime \prime} \mathrm{E}$ and $37^{\circ} 20^{\prime} 36^{\prime \prime} \mathrm{E}$. Among all villages located within a $10 \mathrm{~km}$ radius (265-9046 $\mathrm{m}$ ) from the Gilgel-Gibe dam, sixteen villages were randomly selected for a series of studies aimed to assess the impact of the dam on the health and other sectors (environment, agriculture and economy) following its starting operation in 2004 [8,23-25]. The distribution of these villages by quadrant in the study area is: Quadrant 1 (Q1) in the northeast including Gelan, Gommo, Kobbi and Koticha villages; Quadrant 2 (Q2) in the southeast including Togo, Dalu, Bissola, Yebo, Kara and Yasso; Quadrant 3 (Q3) in the southwest including Dora, Osso, Warsu and Abayota; and Quadrant 4 (Q4) in the northwest including Buddo, and Dogooso villages (Figure 1). Malaria transmission in the area is unstable and seasonal like in other parts of the country [22-25], with P. falciparum and P. vivax accounting respectively for $64 \%$ and $36 \%$ of malaria infections [23]. A previous cohort study that 
followed up children $<10$ years for two years (2008-2010) in the same study area found spatial clusters of higher malaria incidence in Q2 and Q4 [25]. Main economic activities include the cultivation of staple crops (maize, teff and sorghum), cattle and small stock-raising. Most Residents in the study villages belong to the Oromo ethnic group, which is one of the largest ethnic groups in Ethiopia.

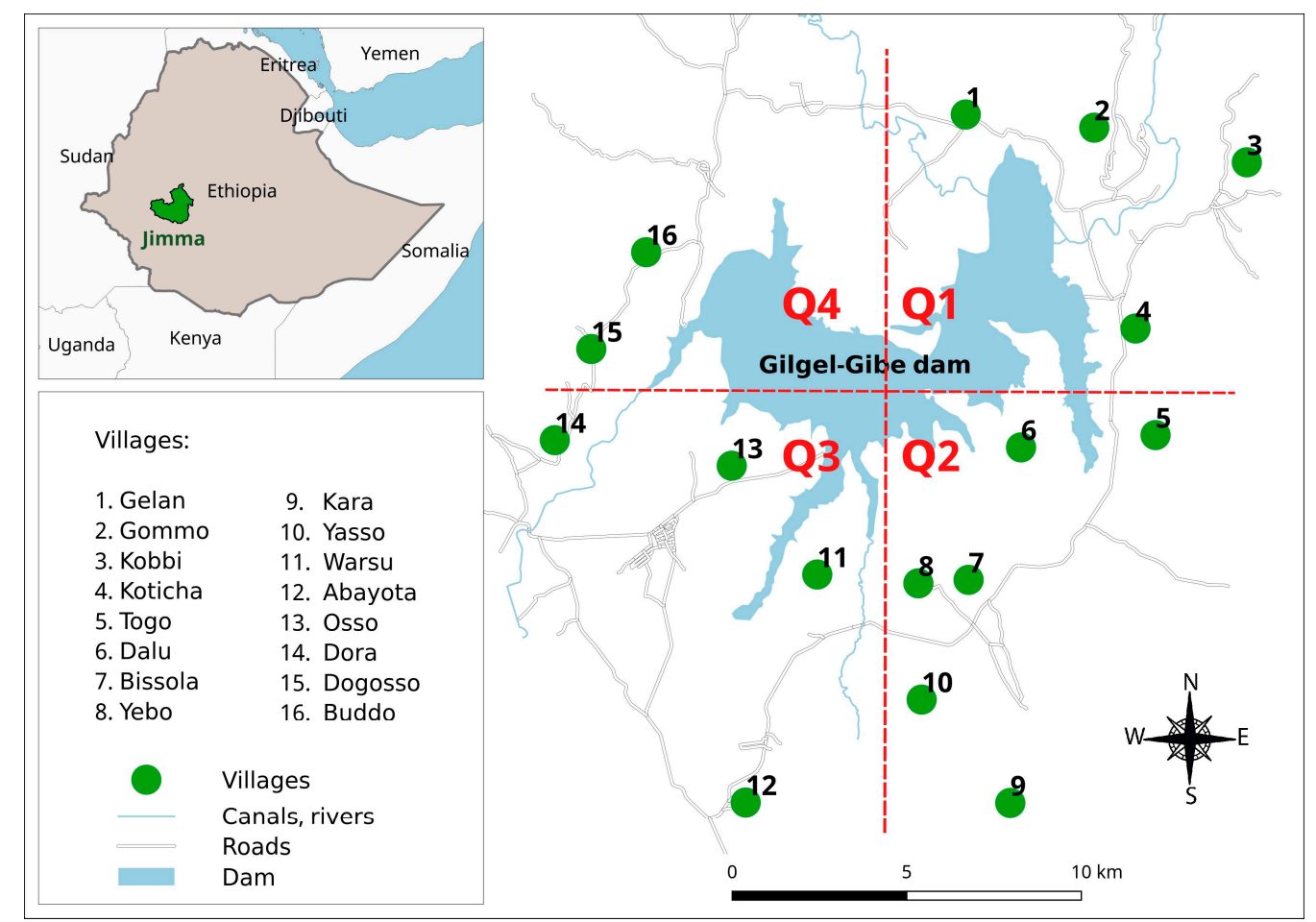

Figure 1. Map showing Jimma zone and study villages around the Gilgel-Gibe hydroelectric dam reservoir, Jimma zone, Ethiopia. Q1 (Quadrant 1) includes Gelan, Gommo, Kobbi and Koticha villages; Q2 (Quadrant 2) includes Togo, Dalu, Bissola, Yebo, Kara and Yasso villages; Q3 (Quadrant 3) includes Dora, Osso, Warsu and Abayota villages; Q4 (Quadrant 4) includes Buddo, and Dogooso villages.

\subsection{Study Design and Population}

A cross-sectional survey was conducted in October-November 2015 (high transmission season) in the study area. The required sample size for the study was 833 households, assuming that $56 \%$ of households owned at least one LLIN [26] and using a precision of 5\%, a significance level of 5\%, a power of $80 \%$, and a non-response rate of $10 \%$ [27]. This sample was equally distributed among the villages, and households in each village were randomly selected from the complete list of households provided by the village administrative offices. A household was defined as any unit headed by a male or female with his/her dependents and/or spouse, and who share a cooking pot/common eating place and sleep under the same roof.

\subsection{Data Collection}

Trained field workers with secondary school level or higher (under supervision of a field coordinator) were in charge of the data collection, using a structured questionnaire and an observational checklist. The English version of the questionnaire was translated into the local language ("Amharic" and "Afan Oromo") and then validated through a pilot-evaluation in a malaria endemic area near the study area. Permission from the village zonal and district administrative offices was obtained before the onset of the study. Each selected household was visited, and a written informed consent was sought from the head of the household. Data were collected on demographics, socio-economic status, housing structure and construction materials, cooking and live stocking practices, history of 
malaria in the past year, discussion/conversation about malaria at household in the past month, as well as on ITN/LLIN ownership, access and use. ITN/LLIN net use the night before the survey was initially established by respondent self-report, and then confirmed after visually verifying that the LLINs were hanging above sleeping spaces.

\subsection{Indicators of LLIN Coverage, Access and Use}

Seven indicators were calculated in the study:

Proportion of households with at least one LLIN $\left(I_{1}\right)$. This indicator provides a measure for household ownership of an LLIN. The numerator includes all households with at least one LLIN and the denominator is the total of number of sampled households [23].

Proportion of households with at least one LLIN for every two family members $\left(I_{2}\right)$. This indicator measures the proportion of households that have enough access to LLIN, i.e., those households with a sufficient number of LLINs to protect all household members. For its calculation, the number of LLIN owned by the household is divided by number of household members. Then, the numerator includes all households that have a LLIN to people ratio of 0.5 or higher, and the denominator is simply the total number of households surveyed [3,28].

Proportion of individuals with access to LLIN within the households $\left(I_{3}\right)$. This indicator estimates the proportion of population that could potentially be covered by the existing LLINs, assuming that each LLIN in a household can be used by two people. The numerator includes all household members who had access to a LLIN, and the denominator is the de-facto population in the sample. The calculation of the indicator was done in two steps [1,7]. First, an intermediate variable "potential LLIN users" was calculated by multiplying the number of LLINs in each household by two. To correct for households with more than one net for every two people, the potential LLIN users were set equal to the members in that household if the potential users exceeded the number of people in the household. Second, the indicator for individual access was calculated by dividing the potential LLIN users by the number of individuals in each household.

Proportion of households with at least one LLIN for every two people among households owning any $\operatorname{LLIN}\left(I_{4}\right)$. This indicator measures the saturation with LLIN in households with any LLIN. Then, the reverse of this indicator $\left(1-I_{4}\right)$ represents the intra-household LLIN ownership gap, i.e., households owning at least one LLIN, but that are not able to cover all household members [29].

Proportion of individuals who slept under LLINs the previous night $\left(I_{5}\right)$. This indicator measures the level of LLIN use in all individuals at the time of the survey. The numerator contains all individuals who slept under a LLIN prior the survey, and the denominator includes the total surveyed population.

Proportion of individuals sleeping under an ITN the previous night among those with access $\left(I_{6}\right)$. This indicator is obtained by dividing the number of people who slept under LLIN the previous night among those with access by the total population who had access to an LLIN. As shown in the description of $I_{3}$, populations with access are the potential LLIN users taking into account that one LLIN is for every two people. Then, the reverse of this indicator $\left(1-I_{6}\right)$ is known as the LLIN behavioral gap, i.e., the proportion of household members who did not sleep under an ITN despite having access to one.

Ratio of LLIN use to LLIN access $\left(I_{7}\right)$. This alternative indicator compares the indicator of individual LLIN use against the indicator of individual LLIN access $\left(I_{7}=I_{5} / I_{3}\right)$, and quickly identifies if the differences between those indicators are mainly explained by behavioral factors.

\subsection{Data Analysis}

The data were entered and cleaned in Excel spread sheets (Microsoft Corp, Redmond, WA, USA), and the analysis was performed with STATA v.14.0 (Stata Statistical Software: Release 14, College Station, TX, USA: StataCorp LP), using the command "svy" [30]. LLIN indicators and corresponding two-sided $95 \%$ confidence intervals (CI) were estimated overall and by quadrant, taking into account the survey design characteristics: village as strata, household as primary sampling 
unit, and corresponding sampling weights (ratio between the sampled households and the total number of households in the village). Univariate and multivariate analysis were performed using survey logistic regression to assess risk factors for households that did not reach at least one LLIN for every two family members (i.e., failure for household access to LLIN), as well as, for households in which the proportion of members that slept under a LLIN the previous night did not reach $80 \%$ (i.e., failure for using LLIN at household). The following potential risk factors were evaluated: demographic characteristics of household head (i.e., age, sex, education level and marital status), housing structure (i.e., predominant material in walls and roof), family size and practices (i.e., cooking practices and livestock ownership), history of malaria in household head and family members in the past 12 months, and discussion/conversation about malaria at household in the past month. Factors with $p<0.2$ for the likelihood ratio test in the univariate survey analysis (intended to assess enough potential risk factors) were considered for inclusion in the multivariate adjusted survey model. Using manual backward methods, final models retained all factors that were significantly associated with failure for household access to LLIN, and failure for using LLIN at household $(p<0.05)$. In addition, a linear regression analysis assessed how $I_{5}$ (LLIN use) and $I_{7}$ (ratio of LLIN use to LLIN access) may be affected by different values of $I_{3}$ (LLIN access).

\section{Results}

The study included 816 households (51 households in each of the 16 selected villages), accounting for 4323 individuals living in them (about 5.3 per household). With a mean age of $43 \pm 13$ years, most heads of households were male $(86.9 \%)$ and had farming $(96.7 \%)$ as their main economic activity. Houses were mainly built of mud walls $(98.5 \%)$ and thatched roofs $(65.2 \%)$. The main fuel used for cooking (53.2\%) was firewood, and almost all households had livestock (94.9\%). A total of $18.2 \%$ household heads and $14.6 \%$ family members reported to have experienced a malaria episode in the past 12 months. Demographic and household characteristics, as well as history of malaria in household members overall and by quadrant are presented in Supplementary Table S1.

\subsection{LLIN Ownership, Access and Use}

In total 1982 ITNs were found in the study villages, from which 1974 (99.5\%) were LLINs (about 1.9 LLINs per household). Table 1 and Table S2 show the estimated indicators of ownership, access and use by quadrant and village, respectively. Overall household ownership of LLINs $\left(I_{1}\right)$ reached $82.7 \%$ (95\% CI: 80.2, 85.1), ranging from $72.2 \%$ (95\% CI: 62.4, 80.2) in villages of Quadrant 4 to $88.0 \%$ (95\% CI: $83.9,91.2$ ) in villages of Quadrant 2. The overall proportion of households with enough LLINs (one LLIN for every two household member) for all their members $\left(I_{2}\right)$ was $68.9 \%$ (95\% CI: 65.6, 71.9), with the lowest values in Quadrant $4(61.5 \%)$ and the highest ones in Quadrant $2(71.2 \%)$.

The overall proportion of population with LLIN access $\left(I_{3}\right)$ was $75.3 \%$ (95\% CI: 68.4, 83.0), while the proportion of population who actually used an LLIN the previous night $\left(I_{5}\right)$ was $63.8 \%$ (95\% CI: 62.3, 65.2). For both indicators (i.e., $I_{3}$ and $I_{5}$ ), the highest values were found in Quadrant 2 and the lowest ones in Quadrant 4. The proportion of households with at least one LLIN for every two people among households owning LLIN $\left(I_{4}\right)$ was above $80 \%$ in all quadrants (overall average: $83.2 ; 95 \%$ CI: $80.3,85.9)$, therefore the overall intra-household LLIN ownership gap $\left(1-I_{4}\right)$ was calculated as $16.8 \%$. On the other hand, the proportion of population sleeping under a LLIN the previous night among those with access was calculated in $89.5 \%$, thus the LLIN behavioral gap $\left(1-I_{6}\right)$ was $10.5 \%$. Moreover, the overall ratio of LLIN use to LLIN access $\left(I_{7}=I_{5} / I_{3}\right)$ was estimated as 0.85 .

A regression model that explains LLIN use $\left(I_{5}\right)$ as function of LLIN access $\left(I_{3}\right)$ predicted that about $95.1 \%$ of the population would use LLINs if the access were universal (100\% of access) (Figure 2a, $p<0.001)$. On the other hand, the regression model that describes the ratio of LLIN use to LLIN access $\left(I_{7}\right)$ as function of LLIN access $\left(I_{3}\right)$ (Figure $2 b$ ) indicated that population access to LLINs $\left(I_{3}\right)$ between $60 \%$ and $100 \%$ would allow achieving ratios of LLIN use to access between 0.8 and 0.9 . 
Table 1. Indicators of ownership, access and use of LLINs in the study area, southwest Ethiopia.

\begin{tabular}{|c|c|c|c|c|c|c|c|c|c|c|c|c|c|c|c|}
\hline \multirow{2}{*}{$\begin{array}{l}\text { Indicator } \\
\text { (Level) }\end{array}$} & \multicolumn{3}{|c|}{ Quadrant 1} & \multicolumn{3}{|c|}{ Quadrant 2} & \multicolumn{3}{|c|}{ Quadrant 3} & \multicolumn{3}{|c|}{ Quadrant 4} & \multicolumn{3}{|c|}{ Total } \\
\hline & $\mathrm{n} / \mathrm{N}$ & $\%$ & $95 \% \mathrm{CI}$ & $\mathrm{n} / \mathrm{N}$ & $\%$ & $95 \%$ CI & $\mathrm{n} / \mathrm{N}$ & $\%$ & $95 \%$ CI & $\mathrm{n} / \mathrm{N}$ & $\%$ & $95 \%$ CI & $\mathrm{n} / \mathrm{N}$ & $\%$ & $95 \% \mathrm{CI}$ \\
\hline$I_{1}(\mathrm{HH})$ & $166 / 204$ & 80.8 & $(75.1,85.6)$ & $269 / 306$ & 88.0 & $(83.9,91.2)$ & $168 / 204$ & 81.1 & $(75.1,85.9)$ & $74 / 102$ & 72.2 & $(62.4,80.2)$ & $677 / 816$ & 82.7 & $(80.0,85.1)$ \\
\hline$I_{2}(\mathrm{HH})$ & $141 / 204$ & 68.6 & $(62.1,74.5)$ & $217 / 306$ & 71.2 & $(66.0,76.1)$ & $143 / 204$ & 68.8 & $(62.1,74.9)$ & $62 / 102$ & 61.5 & $(51.5,70.6)$ & $563 / 816$ & 68.9 & $(65.6,71.9)$ \\
\hline$I_{3}$ (Ind) & $151 / 204$ & 74.2 & $(68.5,79.8)$ & $243 / 306$ & 79.5 & $(75.4,83.4)$ & $154 / 204$ & 75.8 & (70.2, 81.3) & $65 / 102$ & 64.2 & $(55.2,73.2)$ & $614.5 / 816$ & 75.3 & $(68.4,83.0)$ \\
\hline$I_{4}(\mathrm{HH})$ & $141 / 166$ & 84.8 & $(78.3,89.6)$ & $217 / 269$ & 81.0 & $(75.9,85.3)$ & $143 / 168$ & 84.8 & $(78.4,89.6)$ & $62 / 74$ & 85.2 & $75.6,91.5)$ & $563 / 677$ & 83.2 & $(80.3,85.9)$ \\
\hline$I_{5}$ (Ind) & $673 / 1070$ & 62.9 & $(59.9,65.8)$ & $1104 / 1614$ & 68.4 & $(66.1,70.7)$ & $689 / 1058$ & 65.1 & $(62.2,67.9)$ & $292 / 581$ & 50.2 & $(46.1,54.3)$ & $2758 / 4323$ & 63.8 & $(62.3,65.2)$ \\
\hline$I_{6}$ (Ind) & $602 / 665$ & 90.5 & $(87.9,92.6)$ & $918 / 1020$ & 90.0 & $(87.9,91.7)$ & $583 / 641$ & 90.9 & $(88.4,93.0)$ & $271 / 324$ & 83.6 & $(79.1,87.4)$ & $2374 / 2650$ & 89.5 & $(88.3,90.7)$ \\
\hline$I_{7}$ ratio & & 0.85 & $(0.83,0.88)$ & & 0.86 & $(0.85,0.88)$ & & 0.86 & $(0.84,0.89)$ & & 0.78 & $(0.74,0.84)$ & & 0.85 & $(0.79,0.91)$ \\
\hline
\end{tabular}

I: Indicators; HH: household; Ind: individual; n: number of HH or Ind that meet the indicator; N: total number of HH or Ind that were assessed.

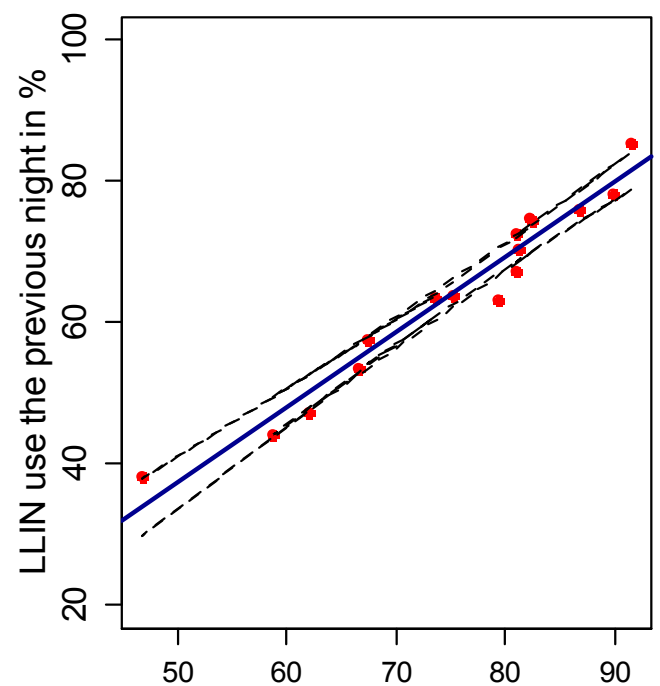

Population with access to LLIN in \%

(a)

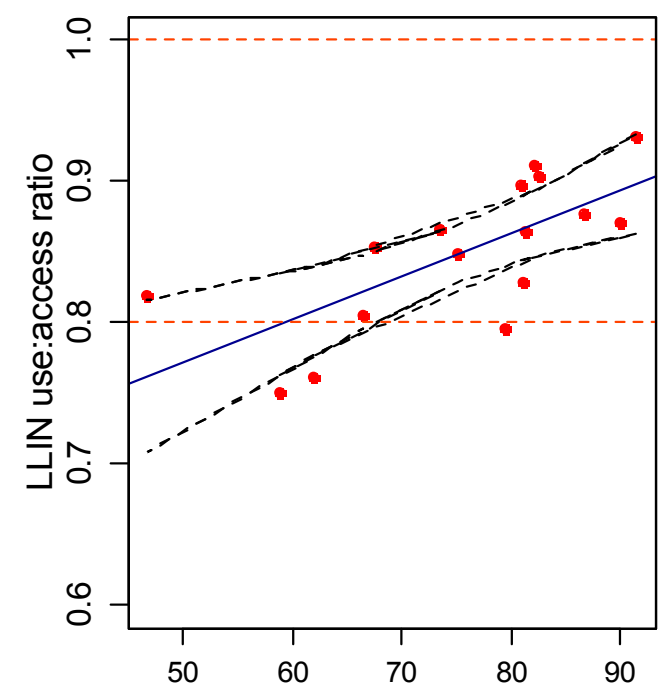

Population with access to LLIN in \%

(b)

Figure 2. (a) Relationship between population LLIN use and population access; and (b) relationship between the ratio of population LLIN use to access, and population LLIN access. The solid blue line represents the predicted values by the linear regression and the black dashed lines are the $95 \%$ confidence intervals of those values. Red points are observed values. 


\subsection{Risk Factors for Failure of Household Access to LLINs and Using LLINs at Household Level}

Age, education, and marital status of household heads, as well as family size and cooking using firewood remained independent risk factors for the failure of a household access to LLINs in the final multivariate model. Households in which heads were between 41 and 50 years old (Adjusted Odds Ratio $(\mathrm{AOR})=1.7 ; 95 \%$ CI: 1.1, 2.8) and older than 50 years old (AOR $=1.9 ; 95 \%$ CI: 1.2, 3.1) were more likely to fail to access LLINs compared to those in which heads were younger than 36 years. Failure of LLIN access was also more common in households where heads were single or divorced $(\mathrm{AOR}=3.8,95 \% \mathrm{CI}: 1.6,9.0)$, and had only primary education level (AOR $=2.6 ; 95 \% \mathrm{CI}: 1.2,5.6)$, or no education $(\mathrm{AOR}=3.1 ; 95 \% \mathrm{CI}: 1.6,6.2)$ compared to households where heads were married and had higher education level, respectively. Households with large families ( $\geq 7$ members) had higher odds of failure to access LLIN (AOR $=9.3 ; 95 \%$ CI: 5.2, 16.8) than households with less than 4 members. In addition, households that used firewood as fuel for cooking were more likely to fail to access LLINs (AOR $=1.7 ; 95 \%$ CI: 1.2, 2.4) compared to those that use other types of fuel (Table 2).

The main independent determinant of failure for using LLINs in a household (i.e., $<80 \%$ of household members that slept under a LLIN the previous night) was the household's access to LLINs. Households with less than one LLIN for every two family members had higher odds (AOR $=36.5$; $95 \%$ CI: 18.5, 71.8) to fail in using LLIN than households with one or more LLIN for every two members. Other factors that remained significant in the final multivariate model for failure for LLIN use at household were the family size and the education level of household head. Indeed, households with 4-6 members (AOR $=7.4,95 \% \mathrm{CI}: 2.6,21.3$ ) and those in which heads had no education (AOR $=2.3$, $95 \%$ CI: 1.2, 4.8) had, respectively, higher odds of failure to have LLIN use than households with three or fewer members, and those in which heads had secondary or higher education level (Table 3). 
Table 2. Univariate and multivariate risk factor analysis for failure to household access to ITNs in southwest Ethiopia ( $\mathrm{N}=816)$.

\begin{tabular}{|c|c|c|c|c|c|c|c|c|c|c|}
\hline \multirow{2}{*}{ Covariates } & & \multicolumn{4}{|c|}{ Failure to HH Access to LLINs } & \multicolumn{3}{|c|}{ Univariate } & \multicolumn{2}{|c|}{ Multivariate } \\
\hline & & $\mathbf{n}$ & $\mathbf{N}$ & $\%$ & $95 \% \mathrm{CI}$ & OR & $95 \%$ CI & $p$ & AOR & $95 \% \mathrm{CI}$ \\
\hline \multirow{4}{*}{ Location of the village } & Quadrant 1 & 63 & 204 & 31.4 & $(25.5,37.9)$ & 1 & & \multirow{4}{*}{0.35} & & \\
\hline & Quadrant 2 & 89 & 306 & 28.7 & $(23.9,33.9)$ & 0.9 & $(0.6,1.3)$ & & & \\
\hline & Quadrant 3 & 61 & 204 & 31.2 & $(25.2,38.0)$ & 0.9 & $(0.6,1.5)$ & & & \\
\hline & Quadrant 4 & 40 & 102 & 38.5 & $(29.4,48.5)$ & 1.4 & $(0.8,2.3)$ & & & \\
\hline \multirow[b]{2}{*}{ Gender of $\mathrm{HH}$ head } & Female & 30 & 103 & 29.6 & $(21.4,39.4)$ & 1 & & \multirow{2}{*}{0.74} & & \\
\hline & Male & 223 & 713 & 31.3 & $(28.0,34.8)$ & 1.1 & $(0.7,1.7)$ & & & \\
\hline \multirow{4}{*}{ Age of the HH head } & $\leq 35$ & 53 & 268 & 19.8 & $(15.5,25.0)$ & 1 & & \multirow{4}{*}{$<0.01$} & 1 & \\
\hline & $36-40$ & 47 & 147 & 31.9 & $(24.8,39.9)$ & 1.9 & $(1.2,3.0)^{*}$ & & 1.0 & $(0.6,1.6)$ \\
\hline & $41-50$ & 80 & 205 & 39.9 & $(33.3,46.9)$ & 2.7 & $(1.8,4.1)^{* *}$ & & 1.7 & $(1.1,2.8)^{*}$ \\
\hline & $>51$ & 73 & 196 & 36.5 & $(29.9,43.6)$ & 2.3 & $(1.5,3.6) * *$ & & 1.9 & $(1.2,3.1) *$ \\
\hline \multirow{3}{*}{ Education of $\mathrm{HH}$} & Above primary & 13 & 99 & 13.8 & $(8.1,22.5)$ & 1 & & \multirow{3}{*}{$<0.01$} & 1 & \\
\hline & Primary & 40 & 142 & 27.7 & $(20.9,35.6)$ & 2.4 & $(1.2,6.3)^{*}$ & & 2.6 & $(1.2,5.6)^{*}$ \\
\hline & No education & 200 & 575 & 13.8 & $31.1,38.9)$ & 3.4 & $(1.8,6.3)^{* *}$ & & 3.1 & $(1.6,6.2) *$ \\
\hline \multirow{3}{*}{ Occupation of $\mathrm{HH}$ head } & Farmer & 245 & 789 & 31.1 & $(27.9,34.4)$ & 1 & & \multirow{3}{*}{0.294} & & \\
\hline & $\begin{array}{l}\text { Government } \\
\text { emplovee }\end{array}$ & 3 & 17 & 19.3 & $(6.3,46.0)$ & 2.2 & $(0.6,7.7)$ & & & \\
\hline & Other & 5 & 10 & 49.5 & $(21.8,77.4)$ & 4.1 & $(0.7,24.1)$ & & & \\
\hline \multirow{3}{*}{ Marital status of $\mathrm{HH}$ head } & Married & 224 & 729 & 30.6 & $(27.4,34.0)$ & 1 & & \multirow{3}{*}{0.049} & 1 & \\
\hline & Widowed & 14 & 54 & 25.9 & $(15.9,39.5)$ & 0.8 & $(0.4,1.5)$ & & 1.3 & $(0.6,2.8)$ \\
\hline & Single/divorced & 15 & 33 & 50.5 & $(33.8,67.2)$ & 2.3 & $(1.1,4.7)^{*}$ & & 3.8 & $(1.6,9.0)$ * \\
\hline \multirow{2}{*}{$\begin{array}{l}\text { History of malaria in the past year } \\
\text { of HH head }\end{array}$} & No & 192 & 664 & 29.2 & $(25.8,32.8)$ & 1 & & \multirow[b]{2}{*}{0.013} & 1 & \\
\hline & Yes & 61 & 152 & 39.8 & $(32.2,47.8)$ & 1.6 & $(1.10,2.33) *$ & & 1.1 & $(0.7,2.0)$ \\
\hline \multirow{3}{*}{ Family size } & $1-3$ persons & 24 & 138 & 18.1 & $(12.5,25.7)$ & 1 & & \multirow{3}{*}{$<0.01$} & 1 & \\
\hline & 4-6 persons & 92 & 451 & 20.4 & $(16.9,24.5)$ & 1.15 & $(0.70,1.91)$ & & 1.5 & $(0.9,2.5)$ \\
\hline & $\geq 7$ persons & 137 & 227 & 60.5 & $(53.9,66.7)$ & 6.9 & $(4.1,11.6)^{* *}$ & & 9.3 & $(5.2,16.9) * *$ \\
\hline \multirow{2}{*}{ Predominant material in $\mathrm{HH}$ walls } & Mud & 248 & 805 & 31 & $(27.9,34.3)$ & 1 & & \multirow{2}{*}{0.571} & & \\
\hline & Cements & 5 & 11 & 39 & $(15.9,68.5)$ & 1.4 & $(0.4,4.9)$ & & & \\
\hline \multirow[b]{2}{*}{ Predominant material in $\mathrm{HH}$ roof } & Iron & 92 & 281 & 32.7 & $(27.3,38.5)$ & 1 & & \multirow[b]{2}{*}{0.496} & & \\
\hline & Thatched & 161 & 535 & 30.3 & $(26.5,34.3)$ & 0.8 & $(0.6,1.2)$ & & & \\
\hline \multirow{2}{*}{ Firewood use for cooking } & No & 118 & 436 & 27.4 & $(23.3,31.8)$ & 1 & & \multirow[b]{2}{*}{0.016} & 1 & \\
\hline & Yes & 135 & 380 & 35.4 & $(30.6,40.3)$ & 1.5 & $(1.1,2.0)^{*}$ & & 1.7 & $(1.2,2.4) *$ \\
\hline \multirow{2}{*}{ Livestock ownership } & No & 10 & 40 & 28.3 & $(16.1,44.8)$ & 1 & & & & \\
\hline & Yes & 243 & 776 & 31.3 & $(28.1,34.6)$ & 1.2 & $(0.5,2.4)$ & 0.707 & & \\
\hline
\end{tabular}


Table 2. Cont

\begin{tabular}{|c|c|c|c|c|c|c|c|c|c|c|}
\hline \multirow{2}{*}{ Covariates } & & \multicolumn{4}{|c|}{ Failure to HH Access to LLINs } & \multicolumn{3}{|c|}{ Univariate } & \multicolumn{2}{|c|}{ Multivariate } \\
\hline & & $\mathrm{n}$ & $\mathbf{N}$ & $\%$ & $95 \%$ CI & OR & $95 \%$ CI & $p$ & AOR & $95 \%$ CI \\
\hline \multirow{2}{*}{$\begin{array}{l}\text { History of malaria in the past year of } \\
\text { any household member }\end{array}$} & No & 199 & 693 & 28.8 & $(25.6,32.3)$ & 1 & \multirow[b]{2}{*}{$(1.3,3.0)^{*}$} & \multirow[b]{2}{*}{$<0.01$} & 1 & \\
\hline & Yes & 54 & 123 & 44.4 & $(35.7,53.5)$ & 2.0 & & & 1.4 & $(0.9,2.4)$ \\
\hline \multirow{2}{*}{ Discussion about malaria in the past month } & No & 70 & 183 & 38.1 & $(31.3,45.3)$ & 1 & \multirow[b]{2}{*}{$(0.5,0.9)$ * } & \multirow[b]{2}{*}{0.021} & 1 & \\
\hline & Yes & 183 & 633 & 29 & $(25.5,32.7)$ & 0.7 & & & 0.7 & $(0.5,1.1)$ \\
\hline
\end{tabular}

Table 3. Univariate and multivariate analysis risk factor analysis for failure for using ITN at household in southwest Ethiopia (N = 816).

\begin{tabular}{|c|c|c|c|c|c|c|c|c|c|c|}
\hline \multirow{2}{*}{ Covariates } & & \multicolumn{4}{|c|}{ Failure for Using LLINs } & \multicolumn{3}{|c|}{ Univariate } & \multicolumn{2}{|c|}{ Multivariate } \\
\hline & & $\mathrm{n}$ & $\mathbf{N}$ & $\%$ & $95 \% \mathrm{CI}$ & OR & $95 \% \mathrm{CI}$ & $p$ & AOR & $95 \% \mathrm{CI}$ \\
\hline \multirow{4}{*}{ Location of the village } & Quadrant 1 & 40 & 166 & 26.4 & $(20.0,34.0)$ & 1 & & \multirow{4}{*}{0.42} & & \\
\hline & Quadrant 2 & 83 & 269 & 30.1 & $(25.7,36.5)$ & 1.2 & $(0.8,1.9)$ & & & \\
\hline & Quadrant 3 & 51 & 168 & 29.9 & $(23.4,37.3)$ & 1.2 & $(0.7,1.9)$ & & & \\
\hline & Quadrant 4 & 28 & 74 & 37.5 & $(26.9,49.4)$ & 1.7 & $(0.9,3.1)$ & & & \\
\hline \multirow{2}{*}{ Gender of HH head } & Female & 23 & 81 & 28.5 & $(19.6,39.5)$ & 1 & & \multirow{2}{*}{0.72} & & \\
\hline & Male & 179 & 596 & 30.5 & $(26.9,34.4)$ & 1.1 & $(0.64,1.86)$ & & & \\
\hline \multirow{4}{*}{ Age of the $\mathrm{HH}$ head } & $\leq 35$ & 60 & 233 & 25.8 & $(20.5,31.8)$ & 1 & \multirow{4}{*}{$\begin{array}{c}(0.8,2.2) \\
(1.1,2.6)^{*} \\
(0.7,1.9)\end{array}$} & \multirow{4}{*}{0.147} & 1 & \\
\hline & $36-40$ & 41 & 127 & 32.3 & $(24.6,41.1)$ & 1.4 & & & 0.8 & $(0.5,1.5)$ \\
\hline & $41-50$ & 60 & 169 & 36.4 & $(29.3,44.0)$ & 1.7 & & & 0.9 & $(0.5,1.6)$ \\
\hline & $>51$ & 41 & 148 & 28.6 & $(21.8,36.7)$ & 1.2 & & & 0.9 & $(0.4,1.7)$ \\
\hline \multirow{3}{*}{ Education of $\mathrm{HH}$} & Above primary & 15 & 94 & 16.7 & $(10.2,26.1)$ & 1 & \multirow{3}{*}{$\begin{array}{l}(0.8,3.1) \\
(1.5,4.8)^{* *}\end{array}$} & \multirow{3}{*}{0.001} & 1 & \\
\hline & Primary & 27 & 116 & 23.6 & $(16.7,32.3)$ & 1.5 & & & 1.4 & $(0.6,2.9)$ \\
\hline & No education & 160 & 467 & 34.7 & $(30.5,39.1)$ & 2.6 & & & 2.3 & $(1.2,4.4)^{*}$ \\
\hline \multirow{3}{*}{ Occupation of $\mathrm{HH}$ head } & Farmer & 195 & 655 & 30.2 & $(26.8,33.8)$ & 1 & \multirow{3}{*}{$\begin{array}{l}(0.2,2.4) \\
(0.5,9.5)\end{array}$} & \multirow{3}{*}{0.56} & & \\
\hline & Government & 4 & 15 & 24.6 & $(9.3,50.8)$ & 0.8 & & & & \\
\hline & Other & 3 & 7 & 47.4 & $(16.7,80.1)$ & 2.1 & & & & \\
\hline \multirow{3}{*}{ Marital status of HH head } & Married & 189 & 614 & 31.2 & $(27.6,35.0)$ & 1 & \multirow{3}{*}{$\begin{array}{l}(0.3,1.3) \\
(0.2,1.8)\end{array}$} & \multirow{3}{*}{0.28} & & \\
\hline & Widowed & 9 & 43 & 21.1 & $(11.1,36.2)$ & 0.6 & & & & \\
\hline & Single/divorced & 4 & 20 & 21.2 & $(18.1,35.1)$ & 0.6 & & & & \\
\hline \multirow{2}{*}{$\begin{array}{l}\text { History of malaria in the past year } \\
\text { of HH head }\end{array}$} & No & 159 & 559 & 28.7 & $(25.0,32.6)$ & 1 & \multirow[b]{2}{*}{$(0.9,2.3)$} & \multirow[b]{2}{*}{0.06} & 1 & \\
\hline & Yes & 43 & 118 & 37.7 & $(29.2,46.9)$ & 1.5 & & & 1.1 & $(0.6,2.0)$ \\
\hline
\end{tabular}


Table 3. Cont

\begin{tabular}{|c|c|c|c|c|c|c|c|c|c|c|}
\hline \multirow{2}{*}{ Covariates } & & \multicolumn{4}{|c|}{ Failure for Using LLINs } & \multicolumn{3}{|c|}{ Univariate } & \multicolumn{2}{|c|}{ Multivariate } \\
\hline & & n & $\mathbf{N}$ & $\%$ & $95 \% \mathrm{CI}$ & OR & $95 \% \mathrm{CI}$ & $p$ & AOR & $95 \% \mathrm{CI}$ \\
\hline \multirow{2}{*}{$\begin{array}{l}\text { History of malaria in the past year } \\
\text { of HH head }\end{array}$} & No & 159 & 559 & 28.7 & $(25.0,32.6)$ & 1 & \multirow[b]{2}{*}{$(0.9,2.3)$} & \multirow[b]{2}{*}{0.06} & 1 & \\
\hline & Yes & 43 & 118 & 37.7 & $(29.2,46.9)$ & 1.5 & & & 1.1 & $(0.6,2.0)$ \\
\hline \multirow{3}{*}{ Family size } & $1-3$ persons & 7 & 117 & 6.5 & $(3.1,13.1)$ & 1 & \multirow{3}{*}{$\begin{array}{l}(2.9,14.7)^{* *} \\
(4.9,26.0)^{* *}\end{array}$} & \multirow{3}{*}{$<0.001$} & 1 & \\
\hline & 4-6 persons & 120 & 388 & 31.4 & $(26.9,36.1)$ & 6.6 & & & 7.4 & $(2.6,21.3) * *$ \\
\hline & $\geq 7$ persons & 75 & 172 & 44 & $(36.6,51.7)$ & 11.3 & & & 2.5 & $(0.8,8.2)$ \\
\hline \multirow{2}{*}{ Predominant material in $\mathrm{HH}$ walls } & Mud & 200 & 669 & 30.3 & $(26.9,33.9)$ & 1 & \multirow[b]{2}{*}{$(0.1,3.8)$} & \multirow[b]{2}{*}{0.7} & & \\
\hline & Cements & $2 / 8$ & 8 & 24 & $(5.7,62.1)$ & 0.7 & & & & \\
\hline \multirow[b]{2}{*}{ Predominant material in $\mathrm{HH}$ roof } & Iron & 62 & 227 & 27.8 & $(22.2,34.1)$ & 1 & \multirow[b]{2}{*}{$(0.8,1.7)$} & \multirow[b]{2}{*}{0.32} & & \\
\hline & Thatched & 140 & 450 & 31.5 & $(27.4,35.9)$ & 1.2 & & & & \\
\hline \multirow{2}{*}{ Firewood use for cooking } & No & 102 & 382 & 27.4 & $(23.1,32.1)$ & 1 & \multirow[b]{2}{*}{$(0.9,1.9)$} & \multirow[b]{2}{*}{0.08} & 1 & \\
\hline & Yes & 100 & 295 & 33.9 & $(28.6,39.6)$ & 1.4 & & & 1.4 & $(0.9,2.2)$ \\
\hline \multirow{2}{*}{ Livestock ownership } & No & 7 & 33 & 22.4 & $(10.9,40.6)$ & 1 & \multirow[b]{2}{*}{$(0.6,3.7)$} & \multirow{2}{*}{0.34} & & \\
\hline & Yes & 195 & 644 & 30.6 & $(27.2,34.3)$ & 1.5 & & & & \\
\hline \multirow{2}{*}{$\begin{array}{l}\text { History of malaria in the past year of any } \\
\text { household member }\end{array}$} & No & 165 & 583 & 28.5 & $(24.9,32.3)$ & 1 & \multirow[b]{2}{*}{$(1.1,2.8)^{*}$} & \multirow{2}{*}{0.01} & 1 & \\
\hline & Yes & 37 & 94 & 41.6 & $(31.9,52.0)$ & 1.8 & & & 1.4 & $(0.7,2.6)$ \\
\hline \multirow{2}{*}{ Discussion about malaria in the past month } & No & 47 & 137 & 34 & $(26.4,42.5)$ & 1 & \multirow[b]{2}{*}{$(0.5,1.2)$} & \multirow{2}{*}{0.28} & & \\
\hline & Yes & 155 & 540 & 29.2 & $(25.6,33.2)$ & 0.8 & & & & \\
\hline \multirow{2}{*}{ HH access to LLINs } & No & 95 & 114 & 83.25 & $(75.12,89.11)$ & 20.3 & \multirow{2}{*}{$(11.9,34.9)^{* *}$} & \multirow{2}{*}{$<0.01$} & 34.0 & \multirow[t]{2}{*}{$(17.1,67.5)^{* *}$} \\
\hline & Yes & 107 & 563 & 19.63 & $(16.54,23.14)$ & 1 & & & 1 & \\
\hline
\end{tabular}




\section{Discussion}

This paper reports the current indicators for LLIN ownership, access and use in a malaria endemic-prone area of southwest Ethiopia, calculated following the recommendations of the Roll Back Malaria Monitoring and Evaluation Reference Group (MERG) [28]. The study area has reached high levels of LLIN ownership, even higher than the previously published regional (58.5\%) and national $(64 \%)$ estimates in 2015 [8]. The national distribution of LLINs in the past three years (about 20 million LLIN between 2014 and 2015) may have contributed to this achievement [8]; however, LLIN ownership levels remained still far below the national goal for 2015 of getting universal coverage (100\%) of LLINs in malaria endemic areas (i.e., all sleeping spaces with LLIN) [11]. Moreover, although the proportion of people $(63.8 \%)$ who used LLIN the previous night in our study was higher than the recent reported figures (33.5\%) of a study in eastern Ethiopia [31], this indicator of LLIN use still remains below the optimal threshold suggested by WHO (80\%) [2,32].

For many years, the outcomes of malaria control with ITNs/LLINs have been assessed using mainly two indicators: the proportion of households with at least one LLIN (household LLIN ownership, $I_{1}$ ) and the proportion of individuals who slept under LLINs the previous night (individual LLIN usage, $I_{4}$ ) [28,33]. However, several studies in endemic areas have described low levels of individual LLIN use $\left(I_{5}\right)$ despite the presence of fair levels of household LLIN ownership $\left(I_{1}\right)[12,14]$. Some of these studies have remarked that the difference between both indicators was mainly explained by an insufficient availability of LLINs to cover all family members (mostly in large families) instead of the complete absence of LLIN at households [34,35]. Similarly, the indicator of individual LLIN use $\left(I_{5}=63.8 \%\right)$ in our study area was not as high as the indicator of household LLIN ownership $\left(I_{1}=82.7 \%\right)$, and indeed the estimated intra-household LLIN ownership gap $\left(1-I_{4}=16.8 \%\right)$ confirmed the need to orient the strategy of LLIN distribution with the aim of reaching enough LLINs to protect all family members at households instead of insuring at least one LLIN per household.

Accordingly, WHO has recently recommended that delivery strategies of LLINs should ensure the availability of one LLIN for every two people [32], and the MERG has incorporated indicators that allow monitoring the access to LLIN appropriately at household (i.e., proportion of households with at least one LLIN for every two household members, $I_{2}$ ) and at individual levels (proportion of individuals with access to LLIN within the household, $I_{3}$ ). Therefore, the levels of both indicators in the study villages (68.9\% and $75.3 \%$, respectively) indicate that current strategies to deliver LLINs (mainly based on free mass distribution campaigns with the operational delivery criteria of one LLIN for every two people [36]) may not be enough to reach universal coverage of LLINs in malaria endemic areas of southwest Ethiopia.

The proportion of the population sleeping under a LLIN the previous night among those with access $\left(I_{6}\right)$, the behavioral LLIN gap $\left(1-I_{6}\right)$ and the population LLIN use to access ratio $\left(I_{7}\right)$ provide complementary information regarding the population use of LLINs. The relative large value of the first indicator $(\sim 90 \%)$ and corresponding low behavioral gap $(\sim 10 \%)$ which contrast with the proportion of the total population sleeping under a LLIN the previous night $\left(I_{5}=62.9-68.4 \%\right)$ in most villages (Quadrants 1-3) further supports the argument that the limited use of LLINs by the population is mainly due to insufficient availability of LLINs in those villages $\left(I_{2}=68.6-71.2 \%\right)$ than due to poor population awareness concerning malaria prevention methods. Similarly, the population LLIN use to access ratio in those villages of around 0.85 confirms that there is not much room for improvement in the population use of LLINs, if only strategies aimed to improve the net use behavior are considered [37]. Conversely, a reduced access to LLIN $\left(I_{2}=61.5 \%\right)$, limited community prevention practices evidenced through an appreciable behavioral LLIN gap $\left(1-I_{6}=16.4 \%\right)$ and a suboptimal LLIN use to access ratio $\left(I_{7}=0.78\right)$ may explain why the lowest values of LLIN use were found in villages of Quadrant 4. Noteworthy, the LLIN use to access ratio in Quadrant 4 was below the mean obtained (0.81) from the analysis of 41 Demographic Health Surveys (DHS) and Malaria Indicator Surveys (MIS) in sub-Saharan Africa [37]. 
Large household size ( $\geq 7$ family members) as the main associated factor for households with insufficient access to LLINs (less than one LLINs for every two persons) is not surprising, and is in line with recent findings in Sierra Leone [38] and Burkina Faso [39] where available ITNs at household were not able to protect all family members. Besides household size, socio-demographic characteristics of household heads and cooking practices using firewood were also independently associated with limited LLIN access. As previously reported in southwest Ethiopia [26], the marital status of household heads was associated with the access to LLIN in our study, with households headed by single or divorced heads four times more likely to lack sufficient access to LLINs than households headed by married couples. A decreased decision-making power in households with a single-parent family structure may explain their lower LLIN access in comparison with household with two-parent families, which may lead to a lower retention of nets (after being delivered) and/or acquisition of nets (in the market) to protect family members against malaria [40]. Moreover, the relationship between the education level of household heads and LLIN ownership has also been studied across several countries of sub-Saharan Africa, with no conclusive results. While a study in eastern Ethiopia found that net ownership was not associated with the education level of household heads [41], other studies in Kenya and Tanzania have reported a significant correlation between education level of household heads and the possession of nets $[19,42,43]$ similar to our study. A higher education level in household heads (as proxy of socioeconomic status) may reflect an increased economic power to acquire LLINs in the market [44], but also may contribute to a better family awareness concerning malaria prevention measures [45]. On the other hand, the lower access to enough LLINs in households with older heads has also been reported in southwest Ethiopia $[26,44]$ and explained by the higher probability for older heads of having larger families. Interestingly, the reduced access to enough LLINs at households in which firewood is used as the main cooking fuel may be explained by a lower perception of the malaria risk due to a decrease in the human-vector contact rate within the house. The repelling effect of the smoke may reduce the indoor density of the malaria vector, giving a perception of protection among family members that likely affects the family decision about acquiring LLINs and/or keeping existing LLINs [46].

The Ethiopian government has committed to achieve malaria elimination in specific geographical areas with historically low malaria transmission and near zero malaria deaths in remaining areas with higher malaria transmission by 2015 [11]. To this effect, the country's goal was that at least $80 \%$ of people at malaria risk use LLINs. In agreement with the analysis of LLIN indicators, the main independent determinant for reduced use of LLINs at households ( $<80 \%$ of household members using LLIN the previous night) in our study area was the insufficient access to LLINs. In other words, without appropriate and universal coverage of LLINs, the Ethiopian malaria control goals for LLIN use will not be reached. Besides strengthening the periodical free mass distribution campaigns of LLINs, there is the need to improve the contribution of the routine distribution through the antenatal care and immunization campaigns [47], as well as to develop alternative strategies such as the distribution of LLINs in schools and the opportune replacement of LLINs by community health workers [48].

The significant reduced use of LLINs in households where heads had no education may be explained by the limited knowledge and wrong perception of family members about malaria and its control, which have repeatedly been reported to be associated with low levels of ITN ownership and use $[14,42,49,50]$. It is well known that despite increasing coverage and ownership of LLINs, the consistent and correct use of the LLINs is not ensured [26]. Information, education and communication (IEC) and behavior change communication (BCC) interventions should always go along with mass distribution campaigns to encourage the correct hanging, preservation, washing, and use of available LLINs [51,52]. After the campaigns, appropriate community communication channels should be used to reinforce the importance of the LLINs for the malaria prevention, and to convince people to use them permanently $[44,52]$. Further research studies including qualitative methods are needed in Ethiopia to better understand how community perceptions and believes influence the sustained use of LLINs at household. 


\section{Conclusions}

Despite the progress made in the last decade, LLIN coverage levels in selected malaria endemic villages of southwest Ethiopia remain below national targets of $100 \%$ for ownership and $80 \%$ for use. The access to enough LLINs within the households as the main restriction of LLIN use in the study area highlights the need to strengthen the current mass distribution campaigns (ensuring always at least one LLIN for every two persons), but also to use alternative mechanisms for continuous distribution of LLINs (e.g., routine distribution through antenatal care, immunization, and replacement of LLINs by community voluntaries). Effective BBC interventions should be implemented before, during and after distribution campaigns to ensure the appropriate and permanent use of LLINs.

Supplementary Materials: The following are available online at www.mdpi.com/1660-4601/14/11/1312/s1, Table S1: Demographics, household characteristics and history of malaria by quadrants in the study area, southwest Ethiopia.

Acknowledgments: We acknowledge the financial support from the Jimma University IUC (Institutional University Cooperation) project in the framework of the Flemish Interuniversity Council (VLIR-UOS).

Author Contributions: Dinberu Seyoum participated in the study design, performed the data cleaning and statistical analysis, and drafted the manuscript. Angel Rosas-Aguirre contributed to the study design and analysis, and drafted the manuscript. Niko Speybroeck contributed the study design and analysis, and critically reviewed the preliminary drafts of the manuscript. Patrick Brandt and Luc Duchateau critically reviewed the preliminary drafts of the manuscript. All authors read and approved the final manuscript.

Conflicts of Interest: The authors declare no conflict of interest.

\section{References}

1. World Health Organization. World Malaria Report (2015); World Health Organization: Geneva, Switzerland, 2015.

2. President Malaria Initiative. Ethiopia Malaria Operation Plan FY 2015. Available online: https:/ / www.pmi.gov/docs/default-source/default-document-library/malaria-operational-plans/ fy-15/fy-2015-ethiopia-malaria-operational-plan.pdf?sfvrsn=3 (accessed on 24 October 2017).

3. Federal Democratic Republic of Ethiopia Ministry of Health. HSDP IV Annual Performance Report 2014/2015. Addis Ababa, Ethiopia. Available online: https:/ /www.pmi.gov (accessed on 8 August 2017).

4. Malaria Prevention through Insecticide Treated Nets. Advocacy Brief. Malaria Consortium, Disease Control. Better Health. Malaria Consortium: London, UK, 2016. Available online: http:/ / www.malariaconsortium. org/media-downloads/802/Malaria\%20prevention\%20through\%20insecticide\%20treated\%20nets (accessed on 8 August 2017).

5. Mugisha, F.; Arinaitwe, J. Sleeping arrangements and mosquito net use among under-fives: Results from the Uganda Demographic and Health Survey. Malar. J. 2003, 2, 40. [CrossRef] [PubMed]

6. Graves, P.M.; Ngondi, J.M.; Hwang, J.; Getachew, A.; Gebre, T.; Mosher, A.W.; Reithinger, R. Factors associated with mosquito net use by individuals in households owning nets in Ethiopia. Malar. J. 2011, 10, 354. [CrossRef] [PubMed]

7. WHO Recommendations for Achieving Universal Coverage with Long-Lasting Insecticidal Nets in Malaria Control (2014). Available online: http://www.who.int/malaria/publications/atoz/who_recommendation_ coverage_llin/en (accessed on 12 August 2017).

8. Ethiopia National Malaria Indicator Survey 2015. Ethiopian Public Health Institute: Addis Ababa, Ethiopia, 2015. Available online: http:/ / www.ephi.gov.et/images/pictures/download2009/MIS-2015-Final-ReportDecember__2016.pdf (accessed on 12 August 2017).

9. Bekele, D.; Belyhun, Y.; Petros, B.; Deressa, W. Assessment of the effect of insecticide-treated nets and indoor residual spraying for malaria control in three rural kebeles of Adami Tulu District, South Central Ethiopia. Malar. J. 2012, 11, 127. [CrossRef] [PubMed]

10. Deribew, A.; Birhanu, Z.; Sena, L.; Dejene, T.; Reda, A.A.; Sudhakar, M.; Deribe, K. The effect of household heads training about the use of treated bed nets on the burden of malaria and anaemia in under-five children: A cluster randomized trial in Ethiopia. Malar. J. 2012, 11, 8. [CrossRef] [PubMed] 
11. National Strategic Plan for Malaria Prevention Control and Elimination in Ethiopia 2011-2015. Addis Ababa. Available online: http:/ / www.nationalplanningcycles.org/sites/default/files/country_docs/Ethiopia/ ethiopia_malaria_national_strategic_plan_2011-2015_130810.pdf (accessed on 12 August 2017).

12. Watiro, A.H.; Awoke, W. Insecticide-treated net ownership and utilization and factors that influence their use in Itang, Gambella region, Ethiopia: Cross-sectional study. Risk Manag. Healthc. Policy 2016, 9, 101. [CrossRef] [PubMed]

13. Shargie, E.B.; Ngondi, J.; Graves, P.M.; Getachew, A.; Hwang, J.; Gebre, T.; Tadesse, Z. Rapid increase in ownership and use of long-lasting insecticidal nets and decrease in prevalence of malaria in three regional States of Ethiopia (2006-2007). J. Trop. Med. 2010. [CrossRef] [PubMed]

14. Atieli, H.E.; Zhou, G.; Afrane, Y.; Lee, M.C.; Mwanzo, I.; Githeko, A.K.; Yan, G. Insecticide-treated net (ITN) ownership, usage, and malaria transmission in the highlands of western Kenya. Parasites Vectors 2011, 4, 113. [CrossRef] [PubMed]

15. World Health Organization. World Malaria Report 2014; World Health Organization: Geneva, Switherland, 2014.

16. Stewart, T.; Marchand, R.P. Factors That Affect the Success and Failure of Insecticide Treated Net Programs for Malaria Control in SE Asia and the Western Pacific; World Health Organization: Geneva, Switherland, 2003.

17. Ruyange, M.M.; Condo, J.; Karema, C.; Binagwaho, A.; Rukundo, A.; Muyirukazi, Y. Factors associated with the non-use of insecticide-treated nets in Rwandan children. Malar. J. 2016, 15, 355. [CrossRef] [PubMed]

18. Ntuku, H.M.; Ruckstuhl, L.; Julo-Réminiac, J.E.; Umesumbu, S.E.; Bokota, A.; Tshefu, A.K.; Lengeler, C. Long-lasting insecticidal net (LLIN) ownership, use and cost of implementation after a mass distribution campaign in Kasaï Occidental Province, Democratic Republic of Congo. Malar. J. 2017, 16, 22. [CrossRef] [PubMed]

19. Teklemariam, Z.; Awoke, A.; Dessie, Y.; Weldegebreal, F. Ownership and utilization of insecticide-treated nets (ITNs) for malaria control in Harari National Regional State, Eastern Ethiopia. Pan Afr. Med. J. 2015, 21, 52. [CrossRef] [PubMed]

20. Berkessa, T.; Oljira, D.; Tesfa, B. Insecticide treated nets use and its determinants among settlers of Southwest Ethiopia. BMC Public Health 2016, 16, 106. [CrossRef] [PubMed]

21. Negash, K.; Haileselassie, B.; Tasew, A.; Ahmed, Y.; Getachew, M. Ownership and utilization of long-lasting insecticide-treated bed nets in Afar, northeast Ethiopia: A cross-sectional study. Pan Afr. Med. J. 2012, 13, 9. [PubMed]

22. Deressa, W.; Fentie, G.; Girma, S.; Reithinger, R. Ownership and use of insecticide-treated nets in Oromia and Amhara Regional States of Ethiopia two years after a nationwide campaign. Trop. Med. Int. Health 2011, 16, 1552-1561. [CrossRef] [PubMed]

23. Yewhalaw, D.; Legesse, W.; Van Bortel, W.; Gebre-Selassie, S.; Kloos, H.; Duchateau, L.; Speybroeck, N. Malaria and water resource development: The case of Gilgel-Gibe hydroelectric dam in Ethiopia. Malar. J. 2009, 8, 21. [CrossRef] [PubMed]

24. Seyoum, D.; Kifle, Y.G.; Rondeau, V.; Yewhalaw, D.; Duchateau, L.; Rosas-Aguirre, A.; Speybroeck, N. Identification of different malaria patterns due to Plasmodium falciparum and Plasmodium vivax in Ethiopian children: A prospective cohort study. Malar. J. 2016, 15, 208. [CrossRef] [PubMed]

25. Seyoum, D.; Yewhalaw, D.; Duchateau, L.; Brandt, P.; Rosas-Aguirre, A.; Speybroeck, N. Household level spatio-temporal analysis of Plasmodium falciparum and Plasmodium vivax malaria in Ethiopia. Parasites Vectors 2017, 10, 196. [CrossRef] [PubMed]

26. Sena, L.D.; Deressa, W.A.; Ali, A.A. Predictors of long-lasting insecticide-treated bed net ownership and utilization: Evidence from community-based cross-sectional comparative study, Southwest Ethiopia. Malar. J. 2013, 12, 406. [CrossRef] [PubMed]

27. Kasiulevičius, V.; Šapoka, V.; Filipavičiūtè, R. Sample size calculation in epidemiological studies. Gerontologija 2006, 7, 225-231.

28. Measure for Evaluation: Roll Back Malaria Partnership. Household Survey Indicators for Malaria Control. June 2013. Available online: http:/ / www.malariasurveys.org/documents/Household\%20Survey\% 20Indicators\%20for\%20Malaria\%20Control.pdf (accessed on 24 October 2017).

29. Animut, A.; Negash, Y.; Kebede, N. Distribution and utilization of vector control strategies in a malarious village of Jabi Tehnan District, north-western Ethiopia. Malar. J. 2014, 13, 356. [CrossRef] [PubMed]

30. StataCorp. Stata Statistical Software: Release 14; StataCorp LP: College Station, TX, USA, 2015. 
31. Gobena, T.; Berhane, Y.; Worku, A. Low long-lasting insecticide nets (LLINs) use among household members for protection against mosquito bite in Kersa, Eastern Ethiopia. BMC Public Health 2012, 12, 914. [CrossRef] [PubMed]

32. World Health Organization. Vector Control Technical Expert Group Report on MPAC. Malaria Policy Advisory Comitee Meeting; World Health Organization: Geneva, Switzerland, 2013.

33. Roll Back Malaria. Guidelines for Core Population-Based Indicators. Geneva: RBM Technical Working Paper No. 1; 2009 [Internet]. Available online: http:/ / reliefweb.int/sites/reliefweb.int/files/resources/ AC719D00E5DE6F5D492575B3001BE5A3-RMB-guideline-20009.pdf (accessed on 12 February 2017).

34. Kilian, A.; Koenker, H.; Baba, E.; Onyefunafoa, E.O.; Selby, R.A.; Lokko, K.; Lynch, M. Universal coverage with insecticide-treated nets-Applying the revised indicators for ownership and use to the Nigeria 2010 malaria indicator survey data. Malar. J. 2013, 12, 314. [CrossRef] [PubMed]

35. Kilian, A.; Koenker, H.; Paintain, L. Estimating population access to insecticide-treated nets from administrative data: Correction factor is needed. Malar. J. 2013, 12, 259. [CrossRef] [PubMed]

36. President Malaria Initiative Ethiopia, Malaria Operation Plan FY 2017. Available online: https: / / www.pmi.gov / docs / default-source/default-document-library/malaria-operational-plans / fy17 / fy-2017-ethiopia-malaria-operational-plan.pdf?sfvrsn=6 (accessed on 24 October 2017).

37. Koenker, H.; Kilian, A. Recalculating the Net Use Gap: A Multi-Country Comparison of ITN Use versus ITN Access. PLoS ONE 2014, 9, e97496. [CrossRef] [PubMed]

38. Bennett, A.; Smith, S.J.; Yambasu, S.; Jambai, A.; Alemu, W.; Kabano, A.; Eisele, T.P. Household possession and use of insecticide-treated mosquito nets in Sierra Leone 6 months after a national mass-distribution campaign. PLoS ONE 2012, 7, e37927. [CrossRef] [PubMed]

39. Samadoulougou, S.; Pearcy, M.; Yé, Y.; Kirakoya-Samadoulougou, F. Progress in coverage of bed net ownership and use in Burkina Faso 2003-2014: Evidence from population-based surveys. Malar. J. 2017, 16, 302. [CrossRef] [PubMed]

40. Bawo, L.L.; Harries, A.D.; Reid, T.; Massaquoi, M.; Jallah-Macauley, R.; Jones, J.J.; Hinneh, L. Coverage and use of insecticide-treated bed nets in households with children aged under five years in Liberia. Public Health Action 2012, 2, 112-116. [CrossRef] [PubMed]

41. Biadgilign, S.; Reda, A.; Kedir, H. Determinants of ownership and utilization of insecticide-treated bed nets for malaria control in eastern Ethiopia. J. Trop. Med. 2012, 2012. [CrossRef] [PubMed]

42. Singh, M.; Brown, G.; Rogerson, S.J. Ownership and use of insecticide-treated nets during pregnancy in sub-Saharan Africa: A review. Malar. J. 2013, 12, 268. [CrossRef] [PubMed]

43. Matovu, F.; Goodman, C.; Wiseman, V.; Mwengee, W. How equitable is bed net ownership and utilisation in Tanzania? A practical application of the principles of horizontal and vertical equity. Malar. J. 2009, 8, 109. [CrossRef] [PubMed]

44. Russell, C.L.; Sallau, A.; Emukah, E.; Graves, P.M.; Noland, G.S.; Ngondi, J.M.; Richards, F.O. Determinants of bed net use in Southeast Nigeria following mass distribution of LLINs: Implications for social behaviour change interventions. PLoS ONE 2015, 10, e0139447. [CrossRef] [PubMed]

45. Singh, R.; Musa, J.; Singh, S.; Ebere, U.V. Knowledge, attitude and practices on malaria among the rural communities in Aliero, Northern Nigeria. J. Fam. Med. Prim. Care 2014, 3, 39. [CrossRef] [PubMed]

46. Gryseels, C.; Uk, S.; Sluydts, V.; Durnez, L.; Phoeuk, P.; Suon, S.; Tho, S. Factors influencing the use of topical repellents: Implications for the effectiveness of malaria elimination strategies. Sci. Rep. 2015, 5, 16847. [CrossRef] [PubMed]

47. World Health Organization (WHO). Global Malaria Programme. Long-Lasting Insecticidal Nets for Malaria Prevention. A Manual for Malaria Programme Managers. 2007. Available online: http:/ /www.who.int/ management/programme/LongLastingInsecticidalNetsMalaria.pdf (accessed on 5 July 2017).

48. De beyl, C.Z.; Asamoah, O.E.; Selby, R.A. Continuous Distribution of LLINs through Primary Schools and Health Facilities in Ghana: Process Evaluation of the Pilot in the Eastern Region (2014). Malaria Consortium, Disease Control, Better Health. Johns Hopkins. Center for Communication Programs. Available online: http:/ / www.malariaconsortium.org/media-downloads/231/Continuous\%20distribution\%20of\% 20LLINs\%20through\%20primary\%20schools\%20and\%20health\%20facilities\%20in\%20Ghana (accessed on 26 October 2017). 
49. Birhanu, Z.; Abebe, L.; Sudhakar, M.; Dissanayake, G.; Yihdego, Y.; Alemayehu, G.; Yewhalaw, D. Access to and use gaps of insecticide-treated nets among communities in Jimma Zone, southwestern Ethiopia: Baseline results from malaria education interventions. BMC Public Health 2015, 15, 1304. [CrossRef] [PubMed]

50. Babalola, S.; Ricotta, E.; Awantang, G.; Lewicky, N.; Koenker, H.; Toso, M. Correlates of Intra-Household ITN Use in Liberia: A Multilevel Analysis of Household Survey Data. PLoS ONE 2016, 11, e0158331. [CrossRef] [PubMed]

51. Koenker, H.; Keating, J.; Alilio, M.; Acosta, A.; Lynch, M.; Nafo-Traore, F. Strategic roles for behaviour change communication in a changing malaria landscape. Malar. J. 2014, 13, 1. [CrossRef] [PubMed]

52. Rosas-Aguirre, A.; Guzmán-Guzmán, M.; Moreno-Gutierrez, D.; Rodriguez-Ferrucci, H.; Vargas-Pacherrez, D.; Acuña-González, Y. Long-lasting insecticide-Treated bednet ownership, retention and usage one year after their distribution in Loreto, Peru. Rev. Peru Med. Exp. Salud Publica 2011, 28, 228-236. [CrossRef] [PubMed]

C 2017 by the authors. Licensee MDPI, Basel, Switzerland. This article is an open access article distributed under the terms and conditions of the Creative Commons Attribution (CC BY) license (http://creativecommons.org/licenses/by/4.0/). 